Transnational Business Governance Interactions Project Working Paper No. 32

June 2018

\title{
Transnational Business Governance Interactions in Food Safety Regulation: Exploring the Promises and Risks of Enrolment
}

Paul Verbruggen

Tilburg University

\section{Tetty Havinga}

Radboud University

This paper is available free of charge from www.tgiforum.org

\section{$X=0$}

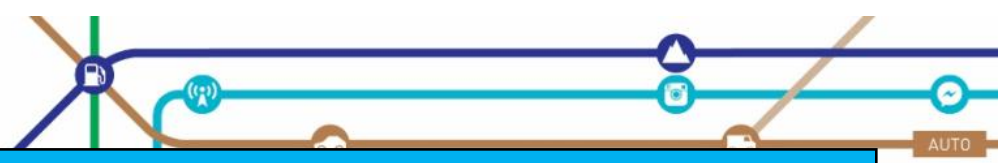

The TBGI Project: Transnational initiatives to regulate business activities interact increasingly with each other and with official regulation, generating complex governance ensembles. Heterogeneous actors and institutions interact at multiple levels and in various ways, from mimicry and cooperation to competition and conflict. The TBGI Project investigates the forms, drivers, mechanisms, dynamics, outputs and impacts of transnational business governance interactions (TBGI) from diverse theoretical and methodological perspectives. It is led by Stepan Wood, Professor and Canada Research Chair in Law, Society and Sustainability at the Peter A. Allard School of Law, University of British Columbia.

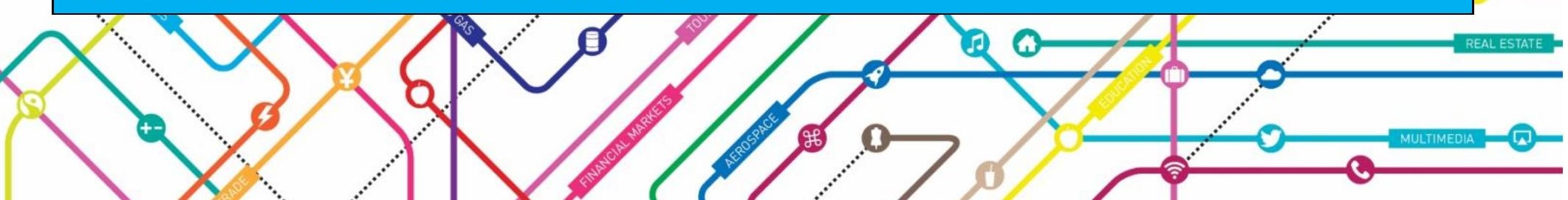


TBGI Project Working Paper No. 32

\title{
Transnational Business Governance Interactions in Food Safety Regulation: Exploring the Promises and Risks of Enrolment
}

\author{
Paul Verbruggen and Tetty Havinga ${ }^{1}$
}

\begin{abstract}
Private actors have assumed an invaluable role in today's global governance of food safety. One of the most prominent private actors in this domain is the Global Food Safety Initiative (GFSI), a nonprofit industry-led organization that benchmarks private food safety standards with a view to coordinate, converge and ratchet up existing standards and enhance compliance with public food safety laws. In this chapter we discuss the unfolding interaction between GFSI and domestic state actors in the regulation of food safety. We offer an empirical account of how and to what extent national food safety agencies in Canada, China and the Netherlands have engaged with GFSI and its benchmarked schemes. We analyse these transnational business governance interactions (TBGIs) using the framework proposed by Eberlein et al (2014) and Wood et al (2015). We show that the interaction between GFSI and public agencies has developed for different reasons and in different ways, with different results. To critically discuss these findings, and to deepen the TGBI analytical framework, we draw on the concept of enrolment as developed by Black (2003). We argue that this concept adds to the TBGI framework a critical perspective on why and how certain actors link with each other, and with what results.
\end{abstract}

\section{Keywords}

Food safety, private standards, certification, Global Food Safety Initiative, enrolment

\section{Introduction}

Food safety regulation has changed profoundly since the 1990s (Verbruggen \& Havinga 2017). The globalization of food supply chains, the growing concentration of market power among food retailers, and systemic risks of food safety outbreaks have each challenged the capacities of national governments to regulate food safety (Marsden et al 2010). Taken together, these developments have also been important elements that triggered the rise of non-state food safety standards (Henson \& Humphrey 2009, p. 9-11). Such standards now govern substantial parts of the global trade in food.

The rise of non-state food safety standards has had a significant impact on actors in global food supply chains. Dominant firms in these chains (typically multinational retailers) require producers and suppliers to meet these standards, effectively shifting compliance costs to actors up the chain. Actors supplying different retailers or markets are often confronted with multiple, partly overlapping standards, each with its own audit and certification protocols. The resulting compliance costs are said

\footnotetext{
1 Paul Verbruggen, Assistant Professor of Global and Comparative Private Law, Tilburg Law School, Tilburg University, the Netherlands. Paul.Verbruggen@uvt.nl. Tetty Havinga, Associate Professor in Sociology and Law, Faculty of Law, Radboud University, the Netherlands. t.havinga@jur.ru.nl. A revised version of this paper is forthcoming in Stepan Wood et al., eds. Transnational Business Governance Interactions: Empowering Marginalized Actors and Enhancing Regulatory Quality. Cheltenham, UK: Edward Elgar.
} 
to impede market access for SMEs, especially those in developing countries (Martens \& Swinnen 2012). This, in turn, has created concerns over the legitimacy of such standards in terms of democratic participation, transparency and accountability (Fuchs et al2009; Casey, this volume).

A group of globally leading retailers established the Global Food Safety Initiative (GFSI) in 2000 in response to these and other concerns (Havinga \& Verbruggen 2017). Rather than developing one single global food safety standard, GFSI benchmarks rival standards following a set of baseline requirements with a view to coordinate, converge and ratchet up existing standards and enhance compliance with food safety laws. GFSI's mission is 'to provide continuous improvement in food safety management systems to ensure confidence in the delivery of safe food to consumers worldwide' (GFSI 2017a).

GFSI actively engages with domestic state actors. Modern food law assigns key monitoring and enforcement competences to national and local authorities on the premise that they are best placed to address local problems and needs (MacMaoláin 2015, p. 54-57). GFSI seeks to gain these authorities' recognition of its activities and benchmarked standards. Concurrently, these domestic state actors have reached out to involve GFSI-benchmarked standards in monitoring and enforcement policies.

In this chapter we discuss the unfolding interaction between GFSI and domestic state actors in the regulation of food safety. We offer an empirical account of how and to what extent national food safety agencies in Canada, China and the Netherlands have engaged with GFSI and its benchmarked schemes. We analyse these transnational business governance interactions (TBGIs) using the framework proposed by Eberlein et al (2014) and Wood et al (2015).

As our analysis will show, the interaction between GFSI and these different actors has developed for different reasons and in different ways, with different results. To critically discuss these findings, and to deepen the TGBI analytical framework, we draw on the concept of enrolment as developed by Black (2003). Regulatory enrolment is considered a strategy for linking actors possessing different regulatory capacities to enhance the capacity of both. It provides 'a normative framework for considering ways in which the capacity of the system as a whole might be enhanced effectively and legitimately by the careful deployment within it of the regulatory capacity of different actors' (Black 2003, p. 91). It adds to the TBGI framework a critical perspective on why and how certain actors link with each other, and with what results.

We start our analysis by discussing the emergence of GFSI as an institutionalized form of TGBIs among non-state food standards.

\section{Institutionalizing TBGIs: The emergence of GFSI}

In 2000, 13 major retailers established GFSI with the purpose of coordinating the transnational food safety standards they developed in the 1990s. As noted, GFSI sets meta-standards for food safety schemes. It assesses whether existing or new food safety schemes meet common benchmarks laid down in the GFSI Guidance Document (GFSI 2017b). Accordingly, GFSI is a transnational metaregulator in the field of private food safety governance (Verbruggen \& Havinga 2016).

Thirteen food safety schemes have been benchmarked against the GFSI Guidance Document (sixth edition) and thus recognized by GFSI. ${ }^{1}$ These include all major schemes around the world. What is more, most leading western corporate food retailers and manufacturers require certification against GFSI-recognized schemes (Havinga 2015, p. 67). Given this strong market uptake, the impact of GFSI on food safety practices on the ground is significant. According to its own statistics, GFSI metastandards find application in 77,000 factories and 150,000 farms in over 160 countries (GFSI 2017c). This implies that GFSI is a key institution in global food safety governance.

While GFSI was born out of a need to coordinate rival food safety schemes, it also has had an impact in terms of converging and ratcheting up the standards that make up these schemes. GFSI's benchmarking standards are widely regarded as the leading industry standard for transnational food safety schemes. Auditing and certification are one domain in which GFSI has been influential in 
shaping the design of these schemes (Fagotto 2017). GFSI helped to establish third party certification as the leading approach to verifying conformity with the applicable standards. With its new Guidance Document, GFSI (2017b) aims to ratchet up industry standards for auditor competence, unannounced audits and fraud prevention (Havinga \& Verbruggen 2017, p. 191).

In the years following its creation, GFSI recognized the importance of engaging with the public sector (Havinga \& Verbruggen 2017). It organized various meetings and events targeted at aligning its activities with national and international governmental organizations (IGOs). It established the Global Regulatory Affairs Working Group in 2009 to 'actively engage governments in recognizing and accepting GFSI benchmarked schemes', further align industry and public sector efforts, and integrate GFSI with the rules of the Codex Alimentarius Commission (Codex) and the Sanitary and Phytosanitary (SPS) Agreement of the World Trade Organization (WTO) (GFSI 2012, p. 3). The Group seeks to forge alliances with state actors by securing governmental recognition of third-party certification to GFSIbenchmarked schemes when determining compliance and enforcement actions, obtaining governmental feedback on GFSI programs, cooperating with governments and IGOs to gain alignment in regulatory capacity-building, and cooperating with Codex and national authorities to harmonize global food safety standards (GFSI 2013).

While these objectives have not been fully achieved, GFSI now participates in discussions on global food governance within Codex and the World Organization for Animal Health (Havinga \& Verbruggen 2017, p. 196-197). It also takes part in regular meetings with officials from national and regional food agencies and has concluded Memoranda of Understanding with several governmental organizations. Our analysis will now focus on these interactions.

\section{TBGIs between GFSI and domestic state actors}

The Global Regulatory Affairs Working Group considered the recognition and adoption of its benchmarked standards by domestic state actors as one of its core deliverables. In many jurisdictions food businesses are legally required (EU, Canada, US) or encouraged (China) to have food safety management systems (FSMSs). Since these systems were first introduced by individual corporations and expanded by non-state food safety schemes and GFSI (Havinga 2006), national laws built on these industry initiatives. GFSI saw the inclusion of FSMS requirements in public legal frameworks as an opportunity for engagement with governments.

In choosing whom to engage with, the Working Group first identified twenty countries of interest. One of the criteria for selection was the willingness of national governments to engage with GFSI. High-priority countries included Canada, Chile, China, Japan, Mexico, South Africa, the Netherlands, UK and US. Alignment with the EU as a whole was also considered a priority. ${ }^{2}$ In 2009 , GFSI representatives met with EU officials as a 'first step in permitting a review of the relationship of food safety schemes to current legislation' (GFSI 2009). The activities of the Working Group included meetings at the national offices in these countries, invitations of senior officers of national food agencies to GFSI conferences and meetings with the GFSI Board, and the sharing of written information about GFSI. The Working Group chair described this effort as:

'(...) a long process of informing the government and officials, getting them to understand more about these standards and GFSI and the fact that it is a global standard and the process that GFSI uses to benchmark the various schemes.' (Havinga \& Verbruggen 2017, p. 199)

In the following we analyse the interactions between GFSI and national governments and food safety agencies by asking why, how and with what results these interactions have taken place. We will focus on the cases of the Netherlands, Canada and China. ${ }^{3}$ We include the Netherlands and Canada because they are considered frontrunners in seeking collaboration with (trans)national food safety schemes and GFSI. In both countries concrete progress has been made toward integration of GFSIbenchmarked schemes in public monitoring and enforcement policies. Moreover, officials of both 
countries are taking the lead in organizing international meetings between representatives of governmental food authorities to discuss options for public-private cooperation. While the Netherlands has now integrated a number of leading foreign schemes in its enforcement policies, Canada's progress is limited to a national scheme recognized by GFSI. We also include China in our analysis since the public-private partnerships that GFSI has established with Chinese state agencies are of a different nature and serve a different purpose when compared to GFSI's engagements with other domestic state actors, namely to resolve structural problems with the benchmarking of Chinese food safety standards.

\subsection{The Netherlands}

Historically, relations between government and industry in the Netherlands are of a corporatist character. The Dutch government has a long tradition of engaging with non-state actors in food policy making. Industry and trade associations established various self-regulatory initiatives that were linked in some way to public policy or legislative frameworks (Van Waarden 1985). As a result, food safety governance in the Netherlands has traditionally involved various forms of industry participation (Havinga \& Van Waarden 2013).

The national food safety authority, the NVWA (Nederlandse Voedsel-en Warenautoriteit), has continued this tradition. NVWA interprets current food safety laws ${ }^{4}$ to enable it to build on private sector initiatives to bolster its risk-based enforcement policies (Verbruggen 2014, p. 238-244). In this context, along with recurring institutional reforms and budget cuts that challenged its regulatory capacities, the NVWA accepted fourteen national non-state quality assurance schemes to inform its enforcement policy. In addition, it concluded memoranda of understanding with seven food companies specifying the terms of collaboration and adapted inspections (Verbruggen \& Havinga 2015).

A new phase in NVWA's engagement with the private sector is its integration of transnational food safety schemes in its enforcement policies. NVWA employs two strategies to influence these schemes and manage how they can be incorporated in its policy in a sound way. First, it challenges GFSI and its benchmarked schemes to strengthen these schemes' performance. Second, it uses an evaluative framework to assess the design of the schemes and their performance. With regard to the first strategy, NVWA officials have met formally and informally with representatives of GFSI, transnational schemes, retailers and brand manufacturers to discuss the conditions under which NVWA accepts certification under these schemes as a factor to influence inspection frequency and enforcement action. Moreover, NVWA officials have spoken at the food safety conferences of GFSI and others, stressing the need to improve the performance of GFSI-benchmarked schemes. The main issues of concern for NVWA are the reliability of third party certification, auditor competences and integrity, unannounced inspections, accreditation, food safety culture at certified businesses, and fraud.

The NVWA's second strategy is the substantive assessment of non-state schemes. Such schemes are only accepted and integrated in NVWA's enforcement policy if they meet key design and performance criteria. After the horsemeat fraud scandal, the Dutch government established a task force of representatives from government, NVWA, the meat, dairy and animal feed industry to discuss measures to restore consumer confidence in food. One result of this process was a policy document stating criteria for acceptance of non-state quality control systems that aim to safeguard food safety and integrity (NVWA 2014). ${ }^{5}$ Transparency and the exchange of information are key elements of these criteria. Twenty two schemes applied for acceptance (NVWA 2017, p. 5). So far the GFSI-recognized schemes of BRC, IFS and FSSC22000 have been accepted. ${ }^{6}$

By recognizing these schemes, NVWA acknowledges that they support public enforcement action. NVWA takes into account whether or not a business is certified against an accepted non-state assurance scheme, for example in decisions about inspection frequency and scope, and sanctions. As a next step in the development of its relations with non-state schemes, NVWA aims 'to establish a 
long term [...] cooperation with scheme owners in order to strengthen the supply chain, exchange information where necessary and support official controls. ${ }^{\prime 7}$

Given these developments and the attitude of NVWA in engaging with industry initiatives, GFSI saw the Netherlands as a key country to successfully align with a domestic state actor. As the chair of GFSI's Regulatory Affairs Working Group commented on NVWA's acceptance of FSSC22000: 'The NVWA is blazing the path for other governmental regulatory authorities to recognize the merits of GFSI-benchmarked schemes, the private assurance system and the benefit of utilizing accredited certifications in helping with the deployment of national inspectional resources, which ultimately leads to a strengthening of the food safety system. ${ }^{8}$

\subsection{Canada}

Canada has a multi-layered governmental system dividing responsibilities for regulations and inspections between the federal, provincial and municipal governments (Hobbs et al 2002, p. 78). The uptake of non-state food safety schemes in governmental policies was until recently mainly limited to export firms. In particular meat export to the US had to comply with strict US regulations. In comparison to the United Kingdom and the Netherlands, the vertical integration of supply chains in Canada is less developed and as a result the role of retailers in driving food safety initiatives is not prominent (Nguyen et al 2004).

However, several food safety incidents demonstrated that the food regulatory framework must be strengthened and keep pace with prevention-focused international food safety standards. In this context, the Canadian Food Inspection Agency (CFIA) sought to modernize its enforcement policy. In considering how to do this, CFIA consulted with many stakeholders, including GFSI. The agency 'recognizes that private certification schemes may play an important role in helping industry achieve food safety regulatory objectives, provided they can be assessed as being effective, credible and aligned with public policy objectives' (CFIA 2016). CFIA's 'Private Certification Policy' notes that certification under a private scheme that meets public law requirements should positively impact the risk-based strategy it uses to prioritize food businesses for inspection. To build this policy, CFIA first assessed whether and to what extent the GFSI Guidance document and the accredited certification process complied with federal legislative requirements. Now that the Private Certification Policy is in place, many food businesses are expected to seek certification from a GFSI-benchmarked scheme in order to comply with the new Safe Food for Canadians Act. ${ }^{9}$

Furthermore, Canada has set up a Food Safety Recognition Program 'which provides government recognition of on-farm and post-farm food safety systems developed and implemented by national industrial organizations' (CFIA 2013). The program is led by CFIA with the participation of provincial and territorial governments. It aims to enhance food safety, maintain the confidence of Canadian consumers and facilitate market access. In 2013 Canadian chicken farmers were the first to achieve recognition under this program, the dairy farmers followed in 2016, and CanadaGAP in 2017. CanadaGAP is a non-state certification scheme for the fruit and vegetable industry that has been benchmarked by GFSI since 2010. Its CFIA recognition process began in 2004 and involved a technical review of the standard and the management system, third party audits to assess implementation and performance, and an evaluation of third party audits by Canadian government officials (CFIA 2017).

Importantly, Canada has also initiated, with the Netherlands, a series of informal meetings between government officials about public cooperation with non-state quality assurance schemes. These meetings include talks with representatives of the GFSI Board. In February 2017, some 100 representatives of twenty national governments and five IGOs met in Houston 'to share information on their approaches to private certification in order to foster a common understanding of benefits and challenges associated with leveraging private certification in regulatory context' (Whitworth 2017). ${ }^{10}$

In 2013, GFSI established a US-Canada Local Group to drive greater regulatory acceptance of GFSI-benchmarked schemes. GFSI advertises the recent CFIA policy framework on private certification schemes, its recognition of CanadaGAP, and its leading role in global meetings to further the 
collaboration between companies and governments to harmonize and strengthen food safety systems around the world. ${ }^{11}$

\subsection{China}

The People's Republic of China has been plagued with major food safety scandals and policymakers in China are increasingly concerned with food safety (An 2017; Burns et al 2015; Jensen \& Zhou 2015, p. 168). The food regulatory system is fragmented and local government is not always willing to enforce the laws due to lack of resources, local protectionism, and corruption (Thompson \& Hu 2007). Food supply chains show little vertical coordination (let alone integration) and food is produced by a large number of low-educated small-scale farmers. Moreover, civil society organizations representing interests of consumers or manufacturers are missing. Industry associations are directly controlled by the government and are not key players in developing and disseminating food safety standards (An 2017).

Before 2009, food safety regulations were more lenient and less sophisticated than transnational food safety standards. The Chinese state has been focussed on the production of high quantities of food and economic growth, not on safe food (Gale \& Buzby 2009, p. 3). After major food safety incidents, high refusal rates in exports, and growing lack of consumer confidence in domestically produced food, the central government established new food safety laws in 2009 and 2015. Along with this legislative overhaul came new systems for effective food controls (Roberts \& Lin 2016). Since then, food businesses are required to have food safety experts and procedures. Compliance with Good Manufacturing Practices (GMP) and Hazard Analysis and Critical Control Points (HACCP) principles is encouraged. Since December 2016, businesses having a GMP or HACCP certificate may be considered to pose less risk to food safety and may benefit from less frequent official inspections. ${ }^{12}$

Despite this regulatory modernization, implementation and compliance remain problematic. Inspection and enforcement are complicated by governmental fragmentation, lack of trained inspectors and insufficient resources (Kottenstede 2017, p. 227-229). Chinese standards and certificates are not considered reliable at the international level (Gale \& Buzby 2009, p. 26). This is a key explanation of why recognition of Chinese food safety standards by GFSI or another international forum that would lend these standards more credibility and authority, is very important for China and its (agri-)food sector.

Since its establishment in 2000, GFSI has developed a close relationship with China and various of its state actors. ${ }^{13}$ China is important for GFSI and its corporate stakeholders: it is a significant market for the production of food and food ingredients, and many food manufacturers in Europe and North America source raw materials from China. GFSI initiates and participates in major food safety events in China. It has created a Chinese website and a Local Group called the China Food Safety Initiative (CSFI). Transnational food safety schemes are in a difficult position to gain access to the Chinese market, as non-state standards need a government licence to operate legally. Only BRC has such a license. Chinese businesses that require a certificate against another transnational scheme to supply to foreign (western) retailers, now contract a foreign certification body accredited under a GFSIrecognized scheme and auditors are flown into China to perform the audits (Kottenstede 2017, p. 230231). The Chinese government prefers certification against the Chinese voluntary public standards (ChinaGAP, China HACCP). As a result of these legal, political and practical hurdles, the market uptake of transnational food safety schemes in China is still limited (An 2017).

GFSI has signed several memoranda of understanding with Chinese accreditation agencies and entered public-private partnerships to enhance food safety in China. ${ }^{14}$ Moreover, the China HACCP scheme applied for GFSI recognition. Since this scheme is effectively government-owned it did not (and could not) meet all requirements specified in the GFSI Guidance Document. For now, China HACCP has been considered technically equivalent to the GFSI requirements. This status applies only to the technical food safety requirements (Part III of the GFSI Guidance Document) and does not include the scheme's governance and operational management components (Part II). ${ }^{15}$ Experts 
remain sceptical about benchmarking Chinese standards against international standards (Kottenstede 2017, p. 229; Interview with a member of the GFSI Regulatory Affairs WG).

GFSl's efforts to recognize China HACCP have led to an interesting development in its benchmarking activities. In 2015, GFSI introduced a new 'Government Standard Equivalence Process' in its Guidance Document. This process is a tool to assess the technical requirements of state-owned certification standards against the GFSI Guidance Document. The governance or operational management of public certification schemes is not assessed. GFSI (2015) presents the process as:

"[...] a positive initiative for building public-private partnerships providing a mechanism for governments to become familiar with the fundamental requirements and principles of the GFSI Guidance Document. It is also hoped that government certification systems will come forward to GFSI to undertake the standard equivalence process enhancing the relationships government and the private sector, in the hope that there is a positive move toward global harmonisation and continuous improvement for food safety systems."

While this new strategy appears to be inspired by GFSI's experience in benchmarking Chinese schemes, it is clearly an attempt to institutionalize the assessment of public food safety certification standards and engage with government organizations at a substantive level. GFSI no longer only seeks to obtain public recognition of its benchmarking of non-state schemes, but now also invites domestic public actors to submit their standards for benchmarking.

\section{Understanding TGBIs: Enrolment in food safety regulation}

GFSI and domestic state actors in the Netherlands, Canada and China have engaged in both formal and informal relations to discuss and implement the integration of transnational food safety schemes in public enforcement policies. To understand better why, how and with what effect these TGBIs emerged, we draw on the concept of regulatory enrolment as developed by Julia Black (2003). ${ }^{16}$ At its core, regulatory enrolment is a strategy for linking actors possessing different regulatory capacities to enhance the capacity of both (Black 2003, p. 84). For Black, regulatory capacity refers to 'the actual or potential possession of resources plus the existence of actual and potential conditions that make it likely that those resources will be deployed both now and in the future in such a way as to further the identified goals of those seeking to regulate (...)' (Black 2003, p. 72). Key resources that shape the regulatory capacity of actors within a regulatory regime are information, expertise, financial and economic resources, authority and legitimacy, strategic position, and organizational capacity (Black 2003, p. 73ff). These resources are not evenly distributed among actors, nor is actors' possession of them static or direct. These characteristics of regulatory capacity - dispersal, change and indirect disposal -invite thinking about ways in which actors possessing different kinds and degrees of regulatory capacity can be linked to one another to enhance the capacity of both actors and the effectiveness of the regime as a whole.

Evidently, regulatory enrolment does not guarantee regulatory outcomes. The actor who is enrolling another does not get full control over the activities of the actor being enrolled. The advantages of the strategy are to be found in the increased capacity of individual actors or the regime as a whole to achieve regulatory goals. For example, by being able to work with more detailed information about regulatory non-compliance provided by auditing firms, state actors may more accurately determine what type of enforcement action is required and refine their approach to secure compliance (Braithwaite 2008, p. 96). Furthermore, the ability to use or rely on additional resources may also enhance the transnational reach of public regulatory activities, which are typically confined to territorial borders (Drahos 2004, p. 418-419). According to Black, a focus on regulatory capacities and their enrolment allows for 'considering ways in which the capacity of the system as a whole might be enhanced effectively and legitimately by the careful deployment within it of the regulatory capacities of different actors' (Black 2003, p. 91). ${ }^{17}$ 
Enrolment therefore provides a critical lens through which to analyze the drivers, modes and results of the interactions between GFSI, transnational schemes and domestic state actors. As we will show, these TBGIs are driven by changes in the configuration of the regulatory resources of the actors involved. Accordingly, enrolment adds to the TBGI framework a focus on regulatory resources as an explanatory variable for interaction and its results.

We will now discuss why, how and with what effect GFSI, transnational schemes and domestic state actors enrol each other in their regulatory activities. As the analysis will reveal, enrolment is not unilateral but mutual: each actor seeks to enrol the capacities of the others to further its own regulatory goals. We distinguish accordingly between four lines of enrolment.

\subsection{Domestic state actors enrolling transnational schemes}

Why do state authorities enrol transnational food safety schemes? The answer is very different for the Netherlands and Canada on the one hand, and China on the other. Dutch and Canadian authorities involve GFSI-benchmarked schemes in their activities principally because these schemes enhance their regulatory resources in several important ways. For one, transnational schemes possess significant audit and enforcement capacity. Audits under these schemes are carried out on (at least) an annual basis and address the full range of food safety requirements that need to be met under binding food safety laws. Consequently, certification bodies possess a wealth of compliance information about the audited firms that is likely to be more up-to-date than the information public agencies possess, given the typically much lower frequency of government inspections. These resources are much needed additions to public food safety agencies' operational resources, which have come under great pressure in the last decade due to budget cuts and increased consumer sensitivity and demand (Garcia Martinez et al 2013). Most agencies do not have the means to perform frequent inspections of all food business operating sites.

The enrolment of transnational schemes in the enforcement policies of public agencies may thus compensate for the gaps in food safety enforcement. It also allows state agencies to deploy their resources more efficiently, to prioritize and focus on controlling high-risk products and underperformers. Firms that participate in a non-state scheme are audited regularly and the costs for these audits are not public expenditures. Moreover, certification against a recognized food safety scheme helps a firm to comply with legal obligations. This is particularly helpful for small firms that lack the expertise to apply the general food safety requirements, such as the HACCP principles (Fairman \& Yapp 2005). Food safety consultants and auditors are contracted by firms to explain food safety laws and to help implement required FSMS. They possess an important strategic position in the regulatory regime in delivering food safety.

Another key reason for domestic state authorities to enrol transnational schemes concerns their strategic positioning in global supply chains (Verbruggen 2016, p. 473-474). The global scale of supply chains poses major challenges for state regulatory capacity. Global supply chains frequently involve stages of production in different jurisdictions. Furthermore, the sheer volume of trade in food products makes assessing compliance with food safety regulation more difficult. ${ }^{18}$ The loss of strategic positioning by national food safety agencies in a global context, a lack of authority and legitimacy to regulate food production in other countries, and the costs of regulating once food products are imported to the home jurisdiction, invite these agencies to think about ways in which they could strengthen their regulatory capacity by enrolling the resources of others. Transnational certification schemes are now enlisted to fill the gap. By doing so, agencies like CFIA and NVWA seek to enrol resources of wealth, strategic position and organisational capacity in ever more globalising supply chains.

In contrast to state actors in the Netherlands and Canada, the Chinese government does not seem to enrol transnational schemes. Rather, it seeks to limit the impact of transnational standards and certification systems in China, and favours national systems (Kottenstede 2017). As noted, foreign schemes are not allowed to operate in China unless they have a licence from the Chinese government. Only BRC applied for and obtained such a license. 
Transnational schemes could enhance the Chinese government's inspection capacity the same as they do for Western governments. However, the Chinese government seems reluctant to enrol these resources as it gives preference to national public standards and inspection by government officials. The recent government policy declaring that food businesses in China having a GMP or HACCP certificate can benefit from a lower inspection frequency may enhance the appeal of voluntary schemes to food business. It is unclear, however, whether this policy also applies to BRC certificates or certificates from transnational food safety schemes based on GMP or HACCP principles.

\subsection{Transnational schemes enrolling domestic state actors}

Since our analysis did not specifically address the regulatory activities of individual transnational schemes but focused on GFSI instead, we have no systematic overview of their considerations and drivers in engaging with domestic state actors. However, we do know from our interviews that major transnational schemes (BRC, IFS, GlobalGAP, FSSC22000, RiskPlaza) have applied under the acceptance scheme operated by NVWA. They met with NVWA representatives and decided to amend their standards to meet NVWA's criteria. A key motive for the schemes to submit to these criteria appears to be that acceptance by NVWA adds to their legitimacy and credibility, and as such strengthens their market position. That market position may be bolstered in two ways. First, food businesses might be more inclined to obtain non-state certification because certification contributes to compliance with public laws and may even result in fewer or modified official controls. Second, accepted non-state schemes become more attractive than schemes that have no public recognition, so their market share will increase. Increased uptake in the market may result in economic gains for the scheme owners and their constituency. For retailers, manufacturers and traders that require their suppliers to be certified against such a scheme, a wider uptake results in a wider choice of suppliers.

\subsection{GFSI enrolling domestic state actors}

GFSl's interest in enrolling domestic state actors lies in its aim to gain recognition for its activities from governments and to strengthen the market position of its constituencies and benchmarked schemes. To achieve these aims, GFSI has sought to raise awareness of its activities and achievements among government officials. It also amended its Benchmarking Guidelines in response to governments' concerns about auditor competence, audit integrity, and equivalence with official inspections. Its activities have begun to bear fruit in that the Dutch and Canadian food safety agencies have recognized a number of GFSI-benchmarked schemes for purposes of their official inspection regimes.

The main resource GFSI and its benchmarked schemes get from such interaction, especially in countries with a highly valued public food safety system, such as the Netherlands and Canada, is legitimacy and authority. Enrolment of credible public authorities compensates for non-state schemes' contested legitimacy in the public domain. Both governments and consumers remain hesitant to rely on such systems to ensure the safety of food. Recognition by a public authority assigns more authority and credibility to non-state systems.

The engagement of state actors with GFSI may also have contributed to the authority and credibility of GSFI and its benchmarked schemes at the substantive level. GFSI responded to concerns of governmental actors about the reliability of third party certification by developing new guidelines on issues such as auditor competence, unannounced visits and food fraud. These guidelines must be met by transnational schemes that apply for recognition at GFSI. The interplay between GFSI and national and international governmental officials so far seems to have contributed to the ratcheting up of dominant transnational food safety schemes.

It should be noted, however, that the relationship between GFSI and China is of a completely different nature. Enrolment of the Chinese government by GFSI is not aimed at increasing its legitimacy and that of transnational schemes. GFSI first and foremost enrols Chinese government institutions to facilitate its constituents' access to the Chinese economy. The Chinese government 
remains the key gatekeeper to the Chinese market, which is important for global food companies that occupy key positions in GFSI.

\subsection{Domestic state actors enrolling GFSI}

National food authorities in the Netherlands and Canada engage with GFSI to tap into its organizational capacity and strategic positioning vis-à-vis transnational schemes. They see GFSI as providing leverage to pressure transnational schemes to change the design of third party certification and improve their performance. A national food authority such as NVWA is in a rather weak position vis-à-vis major global players such as GFSI and BRC. The Netherlands is not a major power and Dutch certified firms represent only a small portion of the global market for transnational food safety schemes. This weakness seems to be outweighed by GFSI's desire to enrol national governments and to highlight successful examples of this collaboration.

The enrolment of other domestic state actors can be a strategy to compensate for the unbalanced relation between domestic agencies and global non-state actors. NVWA is innovative in this regard. It has initiated meetings of national food authorities in Europe to discuss the value of nonstate certification schemes for official food safety controls. Dutch and Canadian government officials also initiated meetings of national governmental officials in the slipstream of the annual GFSI global conferences in Berlin (2016) and Houston (2017). This enrolment of other national governments can strengthen the position of individual agencies vis-à-vis transnational actors.

GFSI plays a fundamentally different role in China than in the other countries addressed here. For the Chinese government the enrolment of GFSI has two distinct advantages. First, it assists the Chinese food industry to comply with more sophisticated food safety requirements. The Chinese government lacks expertise and knowledge regarding food safety assurance. Improving the level of food safety is important for both the Chinese market (as food scandals often have implications for political actors) and for the Chinese export industry (as important export markets require a minimum safety level). Cooperation with GFSI may add to the legitimacy of the Chinese regulatory system, both domestically and internationally. However, so far the Chinese schemes ChinaGAP and ChinaHACCP are not fully recognized by GFSI, and observers remain sceptical about the credibility of their certificates.

The interplay between GFSI and the Chinese government enrols different resources than does the interaction between GFSI and the Netherlands and Canada. This could be attributed to China's state-dominated, authoritarian economic and political system. Public authorities remain at the centre of the Chinese regulatory landscape. The Chinese party-state supports new actors only insofar as they remain controllable (Van Rooij, Stern and Fürst 2016, Kottenstede 2017). Next to the dominant position of the state, the underdeveloped private sector and public distrust of private commercial entities to safeguard public interests such as food safety, have also impeded industry from engaging in regulatory processes in China. Alternatively, the difference could be attributed to the different phases of state engagement with non-state standards organizations. Initially, governments in the Netherlands and Canada also wanted to stay in complete control, but this urge decreased over time as trust in these private sector bodies grew and public officials came to realise the potential advantages of alignment with them.

\section{Promises and risks of enrolment}

Regulatory enrolment is a useful analytical tool to assess why and how regulatory actors seek to interlink with others. It offers insight into the opportunities to strengthen the regulatory capacity of individual actors and the regime as a whole by joining, borrowing or exchanging resources between various actors in the regime. We saw that both domestic state and transnational non-state actors (i.e. GFSI) try to enroll each other in their regulatory activities. Indeed, the process of enrolment in the domain of food safety regulation is characterized by reciprocity, that is, each side enrolls the capacity of the other. The principal driver for this process is the actors' lack of vital resources to deliver their 
regulatory goals, inducing them to team up with other actors that may offer what they need. This idea that joining and borrowing between actors in the face of apparent regulatory incapacities is a driver of TGBI should be considered a key addition of the concept of regulatory enrolment to the TBGI analytical framework.

It would be easy to interpret the strategy of enrolment as a win-win proposition for the enrollers and the enrolled. In particular, in the field of food safety regulation national governments will use the information, wealth and strategic positioning of transnational schemes and, in return, these systems will gain legitimacy, public recognition and a stronger market position. However, the concept of enrolment does not draw sufficient attention to challenges and risks that might be concerned with public-private regulatory collaboration. In this section we will discuss potential risks related to conflicts of interest, non-state schemes' underperformance and state authorities' independence.

First, enrolment triggers a risk of conflicts between public and private interests. Although both government and industry have a clear common interest in the assurance of food safety, private interests do not completely overlap with public interests. For private parties (e.g. individual companies, certification bodies, GFSI) economic interests are important and quite often dominant. Where food safety interests conflict with economic interests, food safety may be disregarded. Companies might be induced to buy cheap products that violate food safety rules, and to omit costly or inconvenient audit procedures. For some companies and in some industries, short-term economic gain dominates and possible loss of reputation matters little. Certification bodies are primarily focused on their customers, who pay for certification and auditing services. This poses a major conflict of interest as these bodies are also expected to advance and assure a public good, namely food safety (Lytton and McAllister 2014). Accordingly, they are in constant limbo between not being too strict with (potential) customers and being strict enough to remain credible. Significant risks also emerge in operationalizing the cooperation between public and private entities. Confidentiality of compliance data, modes of exchange and verification of information about food safety incidents and risks, definition of responsibilities and competences within a cooperative initiative, and demands for public accountability in case of food safety incidents are important issues that may undermine the effectiveness of the whole enterprise (Verbruggen \& Havinga 2015, p. 521-523).

Second, underperformance of non-state food safety schemes may challenge public-private collaboration. Non-state schemes may not be capable or willing to conduct and maintain adequate food safety controls. The actual performance of such schemes has been criticized as too lenient and unreliable. Commentators have noted that these schemes lack enough qualified auditors and largely rely on announced inspection visits and administrative controls to verify compliance (Fagotto 2017). The conflicts of interest inherent in the design of non-state certification question the willingness of certified bodies to enforce food safety rules strictly. In addition, non-state schemes presuppose that audited food businesses are motivated to ensure food safety, but some food businesses may not place top priority on food safety and may be inclined to neglect food safety precautions and cover up noncompliance.

Third, incorporation of non-state food safety schemes in public food inspection policy may challenge state food authorities' independence as law enforcement agencies. By relying on non-state schemes to ensure food safety, public authorities might lose touch with the industry and fail to see what is happening on the ground. This will also eventually undermine the legitimacy and credibility of public food authorities. Regulatory capture is also a risk that emerges when government works closely with industry, as we saw in our discussion of Canada and the Netherlands.

Being aware of these potential risks, domestic state actors discuss with GFSI and non-state scheme owners what they see as these schemes' main weaknesses. They ask schemes to impose stricter standards concerning unannounced audits, auditor competence, integrity and independence, exchange of information on non-compliance, food fraud and authenticity controls, assurance in supply chains, and accreditation of certification bodies. They not only discuss these issues with representatives of GFSI and non-state food safety schemes, the Netherlands and Canadian authorities 
also check how reliable the non-state systems are. Moreover, they have formulated conditions that must be satisfied before non-state certification is taken into account in governmental inspection policy.

Over time, non-state food safety schemes have become more elaborate. Discussions with state officials about their concerns over the design and performance of non-state schemes have contributed to this development. However, it is partly an autonomous development of non-state food safety schemes and the system of third party certification and accreditation. The mutual enrolment as discussed here seems to have resulted in a ratcheting up of non-state schemes. From the perspective of improving food safety this can be considered a positive trend. However, the standards' stricter requirements and increased scope will also make it more costly and difficult for newcomers to join, that is, food businesses that are not certified against a GFSI-benchmarked scheme, and new schemes. Small food businesses and suppliers in developing countries are particular victims of this development. It becomes more and more difficult for them to comply with the increasing demands these schemes impose. Collaboration with non-state schemes also implies a shift of costs from the public expenditure toward private industry. Some private actors can bear these costs (and are happy to bear them because of the autonomy it entails), others cannot.

\section{Enrolment and the TBGI framework}

In this chapter we have argued that the concept of regulatory enrolment is a useful tool to analyze complex interactions between different state and non-state actors in a transnational regulatory regime. The concept focuses on regulatory resources, their fluid and dynamic character, and the ways in which actors draw upon others' resources to bolster or maintain their legitimacy and effectiveness. As such, enrolment helps explain why regulatory actors try to connect and collaborate with other actors. In this respect the concept is a valuable addition to the TBGI analytical framework.

Regulatory enrolment as observed in the field of global food safety regulation is a reciprocal process that strengthens the capacity of actors in the regime and the capacity of the regime as a whole. However, the concept of enrolment does not focus much attention on the possible drawbacks of the interaction between state and non-state actors. In the domain of food safety, and perhaps in others too, the state actors that enrol transnational non-state actors should be aware not only of the opportunities, but also of the risks this strategy entails. These risks should signal to state actors that they must carefully formulate the conditions for collaboration with non-state actors and clearly define their respective responsibilities for the attainment of regulatory goals.

\footnotetext{
${ }^{1} \mathrm{GFSI}$ has 13 recognized schemes from 9 scheme owners, accessed 7 April 2017 at

http://www.mygfsi.com/schemes-certification/recognised-schemes.html.

2 Other focus countries: Australia, Belgium, Brazil, Colombia, France, India, Korea, New Zealand, Peru, Thailand, and Turkey, Global Regulatory Affairs TWG Progress (Sept 2014), accessed 10 February 2016 at<www.mygfsi.com>. GFSI Newsletter 2013 speaks of 15 countries.

3 This analysis summarizes and updates our findings as presented in Havinga \& Verbruggen 2017, 201-210. Our analysis is built on interviews with four respondents at GFSI (2) and Dutch officials (2). We complemented these findings with documentary evidence as publicly available on the Internet. Where such evidence was available, we refer to these public sources.

${ }^{4}$ See in particular the General Food Law (Regulation 178/2002/EC) and the Official Controls Regulation (Regulation 882/2004/EC).

${ }^{5}$ These criteria were modestly revised in September 2017. See: http://ketenborging.nl/wpcontent/uploads/EN-version-Criteria-for-supervision-support-through-private-quality-systems-25-9-17.pdf.

${ }^{6}$ Kwaliteitsschema's en status, accessed 5 December 2017 at http://ketenborging.nl/kwaliteitsschemas-enstatus/

${ }^{7}$ Hans Beuger, Senior officer NVWA, accessed 8 February 2017 at

http://www.fssc22000.com/documents/news-items/fssc-22000-accepted-by-nvwa.xml?lang=en.
} 
8 Joseph Scimeca, Chair Regulatory Affairs Task Force GFSI, accessed 8 February 2017 at http://www.fssc22000.com/documents/news-items/fssc-22000-accepted-by-nvwa.xml?lang=en.

${ }_{9}$ GFSI Focus Days Come to Canada, accessed 28 November 2016 at http://www.mygfsi.com/newsresources/news/425-gfsi-focus-days-come-to-canada-key-time-in-food-safety-regulatory-landscape.html. Safe Food for Canadians Regulations, Canada Gazette 131/3, January 21, 2017.

${ }^{10}$ Agenda and draft summary of the Government-to-government meeting, Houston 2017 February 27th (on file with the authors). See also GFSI news release ' 30 Institutions Come Together with GFSI in a "G30" of Food Safety', myGFSI.com/newsreleases/652.

${ }^{11} \mathrm{GFSI}$ news release 'GFSI-recognised certification programme achieves full government recognition', 20 March 2017; GFSI news release 'GFSI applauds New Canadian Policy on Private Certification of Food Facilities'.

12 Food Safety Law 2009 (as amended in 2015) and Administrative Measures on Determination of Risk Levels of Food Businesses, (CFDA September 2016). Information provided by Yongkang An.

13 See for more details on the relationship between GFSI and China, Kottenstede (2017) and Havinga and Verbruggen (2017).

14 Partnerships include those with the Certification and Accreditation Administration of China and the China Nutrition and Health Food Association, see http://www.mygfsi.com/news-resources/news/news-releases/435leveraging-the-global-food-safety-initiative-to-meet-china-food-safety-challenges.html accessed 28 November 2016; 'GFSI embarks on public-private partnership with China's CNCA to accelerate food safety development', accessed 28 November 2016 at http://www.mygfsi.com/news-resources/news/432-gfsi-embarks-on-publicprivate-partnership-with-china-s-cnca-to-accelerate-food-safety-development.html.

15 This seems to be contrary to the Guidance document ed. 6, which reads: 'The types of scheme that can be recognized by GFSI are schemes owned by nongovernmental bodies or government bodies. Irrespective of ownership, schemes must meet the requirements for application specified in Part II Section 2.' (Part II 1.1, Guidance document 6th ed, version 6.3).

${ }^{16}$ This analysis builds on Verbruggen 2016.

${ }^{17}$ The idea behind regulatory enrolment has been discussed by many others. See for a discussion with relevant references Verbruggen 2016.

${ }^{18}$ The US Food and Drug Agency (FDA) seeks to link to this resource in particular. Since the adoption of the Food Safety Modernization Act (FSMA) in 2011, the FDA require certification schemes to assure that particular imported foods comply with US legal requirements. 'FSMA Final Rule on Accredited Third Party Certification', accessed 12 May 2017 at http://www.fda.gov/Food/GuidanceRegulation/FSMA/ucm361903.htm. 


\section{References}

An, Yongkang (2017), The partial food safety regulatory regime in China. A comparison with the United Kingdom and Germany. Unpublished PhD thesis UCD Dublin.

Black, Julia (2003), 'Enrolling actors in regulatory systems: examples from UK financial services regulation', Public law, 63-91.

Braithwaite, John (2008), Regulatory Capitalism: How it Works, Ideas for Making it Work Better, Cheltenham: Edward Elgar.

Burns, John P. , Jing Li and Xiaoqi Wang (2015), 'The Political Economy of Chinese Food Safety Regulation: Distributing Adulterated Milk Powder in Mainland China and Taiwan', in Tetty Havinga, Frans van Waarden and Donal Casey (eds), The Changing Landscape of Food Governance, Cheltenham, UK and Northhampton, MA, USA: Edward Elgar, pp. 96-113.

CFIA (2013) Food Safety Recognition Program, accessed 5 December 2017 at http://www.inspection.gc.ca/food/safe-food-production-systems/food-safetyenhancement-program/recognition-program/eng/1299860970026/1299861042890.

CFIA (2016), Private Certification Policy, accessed 28 November 2016 at http://www.inspection.gc.ca/about-the-cfia/accountability/consultations/regulatory-riskbased-oversight/private-certification-policy/eng/1452808755126/1452808821799?chap $=0$.

CFIA (2017), CanadaGAP program receives full government recognition accessed 5 December 2017 at http://www.inspection.gc.ca/about-the-cfia/the-cfia-chronicle-edition-3/canadagapsuccessfully-completes-the-canadian-food/eng/1509030448145/1509030448497

Drahos, P. (2004), 'Intellectual Property and Pharmaceutical Markets: A Nodal Governance Approach', Temple Law Review, 77(2), 401-424.

Eberlein, Burkard ,Kenneth W. Abott, Julia Black, Errol Meidinger and Stephan Wood (2014), 'Transnational Business Governance Interactions: Conceptualization and Framework for Analysis', Regulation \& Governance, 8 (1), 14.

Fagotto, Elena (2017), 'Resolving gaps in third-party certification for food safety hybridization', in Paul Verbruggen and Tetty Havinga (eds), Hybridization of food governance: Trends, types and results, Cheltenham, UK and Northhampton, MA, USA: Edward Elgar, pp. 54-77.

Fairman, Robyn and Charlotte Yapp (2005), 'Enforced Self-Regulation, Prescription, and Conceptions of Compliance within Small Businesses: The Impact of Enforcement, Law \& Policy, 27 (4), p. $491-519$.

Fuchs, Doris, Agni Kalfagianni and Tetty Havinga (2011), 'Actors in Private Food Governance: The Legitimacy of Retail Standards and Multistakeholder Initiatives with Civil Society Participation', Agriculture and Human Values, 28 (2), 353-367.

Fulponi, Linda (2006), 'Private voluntary standards in the food system: The perspective of major food retailers in OECD countries', Food Policy, 31, 1-13.

Gale, Fred and Jane B. Buzby (2009), 'Imports From China and Food Safety Issues', Economic Information Bulletin 52.

Garcia Martinez, Marian, Paul Verbruggen and Andrew Fearne (2013), 'Risk-based Approaches to Food Safety Regulation: What Role for Co-regulation?', Journal of Risk Research, 16 (9), pp. 1101-1121

GFSI (2009) Newsletter Summer.

GFSI (2011), Enhancing Food Safety Through Third Party Certification, accessed 28 November 2016 at http://www.mygfsi.com/gfsifiles/GFSI White Paper Enhancing Food Safety Through Third Party Certification.pdf.

GFSI (2012), Newsletter November.

GFSI (2013), The GFSI Global Regulatory Working Group: What is it and what is it doing? accessed 30 September 2015 at <www.ifofs.org/whatsnew/2013-04-04/58.html>.

GFSI (2015), Government Standard Equivalence Process, GFSI Guidance Document Version 6.4 Part III, accessed 5 December 2017 at <http://www.mygfsi.com/news-resources/news/413- 
government-standard-equivalence-process-gfsi-guidance-document-version-6-4-partiii.html>

GFSI (2017a), What is GFSI, accessed 7 April 2017 at www.mygfsi.com.

GFSI (2017b), GFSI Benchmarking Requirements, GFSI Guidance document version 7, accessed 12 May 2017 at www.mygfsi.com.

GFSI (2017c), Infografic, accessed 24 April 2017 at http://www.theconsumergoodsforum.com/images/the_forum_images/strategicfocus/gscp/resources/information_kit/pdf/GFSI_Infographic.pdf

Havinga, Tetty (2006), 'Private regulation of food safety by Supermarkets', Law \& policy, 28 (4), 515533.

Havinga, Tetty (2015), 'Retail driven food safety regulation', in Abdelhakim Hammoudi, Christina Grazia, Yves Surry and Jean-Baptiste Traversac (eds), Food safety, market organization, trade and development, Cham: Springer, pp. 59-76.

Havinga, Tetty and Paul Verbruggen (2017), 'The Global Food Safety Initiative and state actors: Paving the way for hybrid food safety governance', in: Paul Verbruggen and Tetty Havinga (eds), Hybridization of food governance: Trends, types and results, Cheltenham, UK and Northhampton, MA, USA: Edward Elgar, pp. 183-214.

Havinga, Tetty and Frans van Waarden (2013), Veilig voedsel: Toezicht toevertrouwen?, Den Haag: Wetenschappelijke Raad voor het Regeringsbeleid Webpublicatie $\mathrm{nr} 70$, accessed 12 May 2017 at https://www.wrr.nl/publicaties/publicaties/2013/03/14/veilig-voedsel-toezichttoevertrouwen-sectorschets-toezicht-in-de-voedselsector---70.

Henson, Spencer and John Humphrey (2009), 'The Impacts of Private Food Safety Standards on the Food Chain and on Public Standard-Setting Processes', Paper Prepared for FAO/WHO, accessed 1 June 2016 at http://www.fao.org/docrep/012/i1132e/i1132e00.pdf.

Hobbs, Jill.E., Andrew Fearne and John Spriggs (2002), 'Incentive structures for food safety and quality assurance: an international comparison', Food control 13 (2), 77-81.

Jensen, Helen H. \& Jiehong Zhou (2015), 'Food safety regulation and private standards in China', in Abdelhakim Hammoudi, Christina Grazia, Yves Surry and Jean-Baptiste Traversac (eds), Food safety, market organization, trade and development, Cham: Springer, pp. 167-182.

Kottenstede, Kai (2017), 'Transnational private food standards in the People's Republic: Hybridization with Chinese characteristics', in: Paul Verbruggen and Tetty Havinga (eds) Hybridization of food governance: Trends, types and results, Cheltenham, UK and Northhampton, MA, USA: Edward Elgar, pp. 215-239.

MacMaoláin, Caoimhín (2015), Food Law. European, Domestic and International Frameworks, Oxford: Hart Publishing.

Marsden, Terry, Robert Lee, Andrew Flynn and Samarthia Thankappan (2010), The New Regulation and Governance of Food. Beyond the Food Crisis?, New York and London: Routledge.

Martens, Miet and Johan Swinnen (2012), 'Private Standards, Global Food Supply Chains and the Implications for Developing Countries', in Axel Marx and others (eds), Private Standards And Global Governance. Economic, Legal and Political Perspectives, Cheltenham, UK and Northhampton, MA, USA: Edward Elgar, pp. 153-71.

Nguyen, Thanh, Anne Wilcock and May Aung (2004), 'Food safety and quality systems in Canada: An exploratory study', International Journal of Quality \& Reliability Management, 21 (6), 655671.

NVWA (2014), Requirements for the acceptance of quality systems by the Netherlands Food and Consumer Product Safety Authority, accessed 12 May 2017 at http://ketenborging.nl/wpcontent/uploads/Criteria-voor-acceptatie-Engels.pdf.

NVWA (2017), Zesde voortgangsrapportage Plan van aanpak NVWA, accessed 17 May 2017 at https://www.rijksoverheid.nl/ministeries/ministerie-van-economischezaken/documenten/brieven/2017/05/16/zesde-voortgangsrapportage-plan-van-aanpaknvwa. 
Roberts, Michael T. and Ching-Fu Lin (2016), 'China Food Law Update: The 2015 Food Safety Law and Social Governance on Food Safety', Journal of Food law and Policy, 12 (2), 238-263.

Rooij, Benjamin van, Rachel E. Stern and Kathinka Fürst (2016), 'The Authoritarian Logic of Regulatory Pluralism: Understanding China's New Environmental Actors', Regulation \& Governance, 10 (1), 3-13.

Thompson D and Hu Y (2007), 'Food Safety in China', Global Health Governance 1/2, accessed 2 April 2014 at http://ghgi.org/Thompson Food\%20Safety\%20in\%20China.pdf.

Verbruggen, Paul (2014), Enforcing Transnational Private Regulation: A Comparative Analysis of Advertising and Food Safety, Cheltenham, UK and Northhampton, MA, USA: Edward Elgar.

Verbruggen, Paul and Tetty Havinga (2015), 'Food Safety Meta-Controls in the Netherlands', European Journal of Risk Regulation, 6 (4), 512-524

Verbruggen, Paul (2016), 'Understanding the 'New Governance' of Food Safety: Regulatory Enrolment as a Response to Change in Public and Private Power', Cambridge Journal of International and Comparative Law 5 (3), 445-476.

Verbruggen, Paul, and Tetty Havinga (2016), 'The Rise of Transnational Private Meta-Regulators', Tilburg Law Review, 21 (2), 116-143.

Verbruggen, Paul, and Tetty Havinga (eds) (2017), Hybridization of food governance: Trends, types and results. Cheltenham, UK and Northhampton, MA, USA: Edward Elgar.

Waarden, Frans van (1985), 'Varieties of Collective Self-Regulation of Business: the Example of the Dutch Dairy Industry', in Wolfgang Streeck and Philip Schmitter (eds), Private Interest Government. Beyond Market and State, Beverly Hills: Sage, pp. 197-220.

Whitworth, Joe (2017), 'GFSI on SENASICA, benchmarking and Africa, Dispatches from GFSI 2017 in Houston', Food Quality News 4 May, FoodQualityNews.com , last retrieved 8 May 2017.

Wood Stepan, Ken Abbott, Julia Black, Burkard Eberlein and Errol Meidinger (2015), 'The interactive dynamics of transnational business governance: A challenge for transnational legal theory', Transnational Legal Theory, 6 (2), 333-369. 